\title{
Marketing Education, Distance Learning and Hypermedia: Teaching 'Current Issues in Marketing' in a Virtual Campus
}

\author{
Gerard Ryan \\ Escola Universitària del Maresme-UPF, Barcelona, Spain \\ Mireia Valverde \\ University of Rovira i Virgili, Tarragona, Spain \\ Inma Rodríguez-Ardura \\ Internet Interdisciplinary Institute, \\ Open University of Catalonia (Universitat Oberta de Catalunya or UOC), Barcelona, Spain

\begin{abstract}
Author Posting. (c) 'Copyright Holder', 2001.
This is the author's version of the work. It is posted here for personal use, not for redistribution.

The definitive version was published in Marketing Education Review, Volume 11 Issue 3, Fall
\end{abstract} \\ 2001.
}

\begin{abstract}
This article reports on a project at the Universitat Oberta de Catalunya (UOC: The Open University of Catalonia, Barcelona) to develop an innovative package of hypermediabased learning materials for a new course entitled 'Current Issues in Marketing'. The UOC is a distance university entirely based on a virtual campus. The learning materials project was undertaken in order to benefit from the advantages which new communication technologies offer to the teaching of marketing in distance education. The article reviews the main issues involved in incorporating new technologies in learning materials, the development of the learning materials, and their functioning within the hypermedia based virtual campus of the UOC. An empirical study is then carried out in order to evaluate the attitudes of students to the project. Finally, suggestions for improving similar projects in the future are put forward.
\end{abstract}

The authors would sincerely like to thank the reviewers of this paper for their valuable comments which have contributed to the improvement of this paper. 


\section{Introduction}

The purpose of this article is to describe a project undertaken by the Department of Economics and Business Studies at the Universitat Oberta de Catalunya (UOC - Open University of Catalonia) to develop a set of hypermedia-based learning materials for one of its subjects, namely, "Current Issues in Marketing" (from here on, CIM). This paper examines the literature on the use of hypermedia materials in distance education, the background to the CIM project, including the issues and challenges faced by the authors, and an empirical study measuring the attitudes of students who have studied using these new learning materials.

\section{Literature Review}

\section{Distance Learning: Definitions \& Background}

Although distance education has been defined in numerous and diverse ways by various authors, it is generally associated with "openness" and "flexibility". The Further Education Funding Council (1997) defines distance education programmes as those in which "students study with specially prepared learning materials for their private study and are provided with a marking and comment service for their written work which may also be accompanied by some counselling or tutorial support [...] This definition is intended to cover situations where study is essentially home based and there is only occasional contact with the institution."(p.25).

According to Johnston (1997), distance learning represents "the bringing together of teachers, learners, information, resources and learning support systems in a place (real or virtual) beyond the confines of the host institution" (p.108). This definition fits more accurately the teaching model of the UOC, which brings all of these elements together in a virtual campus, as will be seen later in this paper.

The creation of the Open University in Great Britain in 1969 marked the beginning of a period of significant development and expansion in university education in general (Holmberg, 1995) with its emphasis on flexible study methods for an adult population who could now study at home with specially prepared learning materials. However, the main concern in distance education for many years afterwards was the sense of 'isolation' often felt by distance education students (Twigg, 1997; Besser \& Donahue, 1996; Hill, 1997), which leds to high dropout rates (Kember, 1989). Thus, much emphasis has been placed on the development and provision of the means of communication between the members of the university community, with the objective of overcoming this potential isolation of students and enabling group activities in a shared 'space' or 'place' (Meacham \& Evans 1989; Abrahamson, 1998).

In recent years, the introduction of new information and communications technologies has enabled greater speed and efficiency in the communication process among the entire university community in distance education (Hara \& Kling, 1999). Computer-mediated communications that do not require either the physical or temporal coincidence of the participants facilitate and promote collaboration and group activities, and help students to feel they are part of a university community, thus reducing the sense of isolation (Levin \& Waddoups, 2000). Indeed the technology does not act merely as a medium for 
the transmission of the message, it also provides a space within which more 'human' activities may be developed (Jones, 1995). For instance, in a virtual campus, individuals are free to 'interact' with others whom they encounter in the virtual spaces (such as virtual bar or cafeteria areas, virtual forums or debate spaces).

One of the most important developments in educational technology is that of hypermedia learning materials. These materials incorporate a range of different media including video, sound, image, internet and text into one integrated packaged based on a web page format. The integration of the different media is made possible by simply clicking on hyperlinks.

Some previous research has been carried out on the use of web based hypermedia learning materials (Viali, 1998, Matrinez, 2000). However much of this is 'more anecdotal than systematically empirical or critical (Hara \& Kling, 1999). This paper will add to the current literature by examining an empirical study of the use of hypermedia learning materials in marketing education in a distance university.

\section{Benefits of New Educational Technologies for the Learning Process}

Besides overcoming student isolation, the incorporation of new technologies in distance education also brings with it a series of potential benefits for the learning process, as well as a number of new challenges. These issues are outlined below.

- Flexibility: The flexibility of the learning process has improved in terms of space and time as a result of new technologies (European Commission, 1998). "Many students registering for online distance education courses are interested in the flexibility this medium of education provides” (Levin \& Waddoups, 2000, p.4). Students can now study where they want and when they want, with access to a wide range of online materials.

- Access to information: New technologies (particularly the internet) facilitate access to a greater and wider number of sources of information (Holmberg, 1995; Butler, 1997) and variety of contents and teaching resources (European Commission, 1998; Sangrà, 2001; Jefferies \& Hussain, 1998) than is possible with traditional distance learning media, such as the 'classic' technologies of analogue video and audio, tv and radio programs and printed learning materials.

- Updateable: New forms of learning materials based on hyper or multi-media formats are generally more easily and more economically updated (Cooke \& Veach, 1997). A major advantage of electronic teaching materials is that information, dates, examples etc. can easily be updated and changes quickly included in the software or computer files sent to students. Students will benefit from more up-to-date materials, including examples, references and support materials.

\section{Challenges of New educational Technologies for the Learning Process}

The incorporation of new technologies in learning materials presents a number of challenges for authors/professors and students alike. Some of these challenges are outlined as follows. 
- Longer production process: In the authors' experience the production of hypermedia based materials requires a significantly longer time period than producing traditional paper based learning materials. The lengthening of the process is due to the involvement of a wider range of external inputs (such as CDROM production), technical support (web page and database design) and the sourcing of all the internet links, images, videos etc.

- Author training: The principles for well-designed hypermedia materials are different from those of paper materials (Hall, 1999). Authors should be made aware of these new design principles. This requires a substantial investment in author training. A significant departure in the design principles of hypermedia materials is the paradigm change from the lineal structure of paper materials to the hyperlink structure of hypermedia materials (Kolosseus et al, 1995).

- Proactive role of student in learning: From the point of view of the student, the new hypermedia environment characterised by its combination of hypertext links and multimedia technologies, requires a new approach to studying. Traditional paper-based learning materials are designed to be read sequentially starting with page one, chapter one and following the contents by the order decided by the author. In contrast, hypermedia learning materials require the initiative and active role of the student (Weiland \& Shneiderman, 1989; Rice \& Ryan, 1999; Sangrà, 2001) in choosing the route to be taken through the contents and the related hypertext links to examples, video clips, and related internet based. However, the change from student-directed linear materials to student-driven hypertext materials is not necessarily an easy one and may be potentially confusing. Students who have difficulty in dealing with the complexity of this new form of reading/studying have been referred to as 'lost in hyperspace' (Burbules \& Callister, 1996).

Interestingly, despite the advantages of new technologies, printed learning materials have remained the dominant media in distance education in Europe (Hagan, 1995) as confirmed by a study realised by the TEEODE Project (Technology Enhanced Evaluation in Open and Distance Education, 1998). According to this study of education institutions of the European Union the use of new technologies such as internet and email (pp.26-27) is very much the exception to the rule.

\section{Description of the Open University of Catalonia (UOC): The 'Virtual Campus'}

The review of the literature has examined the role of new technologies in distance education. This paper reports on a specific project (Current issues in Marketing - CIM) incorporating new hypermedia technologies in the learning materials of the Open University of Catalonia (UOC). Before dealing with the empirical study that examined students attitudes to the new hypermedia learning materials, it is important to describe the university and the CIM project. The remainder of the paper will take the following structure, as outlined below;

Description of the Virtual Campus -> CIM Project: Objectives and Learning Materials -

$>$ Empirical Study. Students’ Attitudes to CIM Materials Assessment -> Discussion and Conclusions 
As the UOC is a distance education university with a specific pedagogical model entirely based on a virtual campus (this campus exists only and exclusively in cyberspace), it will be necessary to begin with a description and discussion of its main characteristics, as they represent the framework in which the CIM project was developed.

The Open University of Catalonia (UOC) began its first academic year in 1995. Crucially at this point in time both personal computers and internet access had become sufficiently affordable to make them widely available to the majority of the population in Catalonia.

In this context, the UOC was effectively the first university fully conceived and based on a Virtual Campus (Warden, 1995), and its initiative was acknowledged by the European Union when granting the UOC the Bangemann Challenge Award in 1997. Indeed, technology allowed the UOC to create a distance university 'without distances' in time or space and in so doing overcame the previously mentioned 'isolation' associated with distance education.

The UOC began by offering two degrees (Business Studies and the Psychology of Education) to 200 students in 1995, and it now caters for over 20.000 students, offering 11 degrees, a range of post-graduate and continuous education courses and a doctorate.

\section{Characteristics of the UOC}

The UOC's educational model is based on five basic elements (Aparicio-Valverde et al., 1996; Borges, 1998) as outlined below;

\section{The Virtual Campus}

Interaction and communication between the members of the UOC take place in the Intranet of the university. This network permits:

- Formal and informal communication;

- Access to university services (electronic library, administrative services, information technology help service, the student co-op, etc);

- Access to internal and external databases.

\section{Educational Materials}

Each module offered by the UOC has a corresponding set of learning materials which combine printed material with multimedia elements, such as diskettes, CD's, videos, and World Wide Web pages and study activities which take place in the virtual classrooms (see next section).

\section{Face-to-face aspects: Meetings and Support Centres}

Students and lecturers come face-to-face in a real (physical) classroom at the beginning and end of each semester. Additionally, the Support Centres, distributed throughout Catalonia, offer students a "physical" place where they can meet to work in groups and have access to (traditional) libraries.

4. The Role of the Professors

The UOC has three types of teachers/professors; 
Co-ordinating Professors are responsible for the organisation and co-ordination of the UOC's teaching (managing the process of developing materials, selection of other lecturers, research, etc.).

Personal Tutors are responsible for orienting the students and monitoring their progress throughout their entire university career. The tutor's intervention is an essential part into making the students feel real members of the university community.

Teacher Professors are responsible for the teaching of each specific module. They help students by orienting them on the use of the subject's learning materials, solving and answering questions, etc.

\section{The Student}

The most common characteristic of UOC students is the fact that they combine working with studying at university (93\% of all UOC students are in employment). Otherwise the profile of the UOC student is quite heterogeneous. Student ages range from 18 to 70 , (even though one third of all students are between 25 and 35 years of age). Time dedicated to study varies according to modules taken each semester (from full time dedication to as little as one subject per semester). Many UOC students left education on completing secondary school in order to enter the workforce and return to education some years latter to study for a university degree.

\section{The Virtual Classroom}

As in traditional university education, the main focus of learning in the Virtual Campus is the classroom, in the case of the UOC, the virtual classroom. The design of this virtual classroom and all its component elements is the core of the UOC pedagogical model. The model was designed for the specific case of the UOC and involved close collaboration between educational and technical specialists.

The typical number of students in a degree course virtual classroom ranges from 50 to 70. Just as in the case of traditional universities where all classrooms contain the same basic design elements such as chairs, tables, blackboards, projectors, etc., all virtual classrooms are provided to professors with common or standard features. We will now briefly describe these features.

Figure 1 about here.

The entrance to the virtual classrooms is illustrated in figure 1. In this particular case the student can choose to enter one of three classrooms or subjects where it says Assignatures (because this student is registered for three subjects in this particular term). Each classroom has three separate areas (where it says 'bústies'); starting from left to right, the professors desk ('tauler de prof') to which all members of the class have access but only the professor may post messages concerning the course, such as explanations of concepts, exercises, guidelines, news and events, deadlines, etc; the debating room ('debats') in which the tutor leads debates on issues relating to the contents of the learning materials; and the forum, a more informal space where students and professor alike may exchange information, post messages, hints, ideas, suggestions, etc. 
All classrooms also include direct access to the library (biblioteca), the student's grades for course exercises (registre d'avaluació continuada), all information regarding the course program and calendar (pla docent), complimentary learning materials for the course (material associat), a list of class members with their CVs, photos and email addresses, and the classroom web, a space where students may exchange files and other documents. (For a more thorough explanation of the virtual classroom, see http://www.uoc.es/extern/an/demo.d/home/home.htm).

A number of conclusions may be drawn regarding the UOC model in relation to the previous review of the literature. Firstly, this model clearly avoids the student 'isolation' traditionally associated with distance education by providing a 'place' (in hyperspace) which unites all members of the UOC community. Secondly, it provides an extremely flexible approach to distance education uninhibited by the limitations of time and space (although lecturers are not required to be constantly online, or do not follow a specific time schedule, all students messages or enquiries must be answered within 48 hours). Thirdly, and most significantly in terms of this paper, the virtual campus of the UOC is conducive to use of hypermedia learning materials as all its students are trained and accustomed in the use of PCs, internet and multimedia materials.

\section{CIM Project: Objectives and Learning Materials}

This section will describe the project to develop hypermedia learning materials for the subject Current Issues in Marketing (CIM). In September 1997 the decision was taken by the Department of Economics and Business Administration of the UOC to develop a hypermedia-based package of learning materials for this new, year 3, optional module.

The objective of this project was to reap the potential benefits of new communications technologies for distance education and to face the challenges that such a project would produce, as identified in the review of the literature. More specifically, the objectives were (these objectives will be used later in this paper as a guide to the formulation of the indicators of the survey instrument):

1. Access to information: The CIM learning materials should facilitate direct access to a greater and wider number of sources of related information and learning materials found on the internet, than is the case with traditional paper learning materials.

2. Updateable: The CIM materials should facilitate constant and effortless updating of their contents. This made particular sense given the fact that the new course was to be on 'current' issues in marketing and would require constant revisions if the contents were to remain 'current'.

3. Proactive role of student in learning: The project should produce a learning package with a significant interactive element, in terms of requiring the active participation and initiative of students in deciding the route through the materials, which related internet resources to use, etc.

4. Adequacy of learning contents to hypermedia platform: It was important to ensure that the contents of the course chosen for this project would be suitable for a 
hypermedia-based learning package. Current Issues in Marketing was an ideal candidate.

The course was divided into four major topics. The topics were chosen taking into account the year 3 students' previous education in marketing, the extent to which the topics were 'current issues' and the advantages that hypermedia materials could offer the study of each topic. The suitability of hypermedia materials was argued as follows:

- International Marketing: Hypermedia materials would facilitate access to the internet sites of international companies throughout the world and would enable close comparison of the regional differences in these companys' strategies by providing access to the local versions of their websites. Internet links would also enable students to access information on legal and regulatory aspects of international marketing, advertising in different countries and regions, national chambers of commerce, international statistical information, etc.

- Internet Marketing: The study of internet marketing obviously requires that students use the internet as a central element of their study. The hypermedia format facilitates instant access to the examples of websites provided in the learning materials.

- Green Marketing: Although it was felt that no specific aspect of this topic made it any more suitable for hypermedia learning materials than many other topics, it was noted that avoiding the use of paper in the production of the materials deserved special emphasis given the philosophy of green or ecological marketing!

- Postmodern Marketing: The study of postmodern marketing requires the examination and comparison of many different media types such as TV advertisements and TV programs, outdoor advertising and internet pages.

Description of the Resulting Learning Materials for CIM

The development of the learning materials was carried out by a team of four professors in Marketing from various universities in Spain. Three of them were already acquainted with the UOC teaching model as they had worked as teacher professors and coordinating professors at the university (see section on Characteristics of the UOC- 4. The Role of the Professors).

The production of the learning materials involved two stages: In an initial stage, the Material Development Unit of the UOC trained the authors in the principles of the design of hypermedia materials (such as the fact that text on a single page should be limited, that scrolling should be avoided, to use multiple columns on the screen, to use images in combination with text, to use linking to allow the reader more control in the reading process). The second stage involved an ongoing review of progress between the Unit and the authors in order to monitor the materials development and to consider the more practical issues (such as copyright for internet based materials and links, number of graphics, video clips etc.).

The materials were completed in September of 1999 and the first group of students began the course in October of the same year. This section briefly describes the main elements and features of the materials for this course. 
The learning materials are accessed directly from the virtual classroom by clicking on the icon 'associated materials' (materials associats). The contents may be downloaded to the student's PC to facilitate off-line study, thus reducing the student's telephone bill, but must be used online if the student wishes to use internet links. Each student is provided with a series of CD-ROMs containing videos of advertisements and TV programs related to the course.

Figure 2 about here

As illustrated in figure 2, the learning materials are based on web pages and may be viewed through any html web browser. Figure 2 shows a typical example of the computer screen of the student, with two separate daughter-windows open in order to access web pages and video clips. In this example, the contents refer to the IKEA approach and philosophy of furniture sales. By clicking on 'IKEA' a separate window appears with the web page of the company in question. Student activities and short exercises may involve examining the information provided by these pages and answering a series of related questions. By clicking on the video camera icon, the student may view an example of one of the company's TV advertisements and consider related questions. The advantages of the use of hypermedia resources are obvious. Instead of merely referring to an advertisement of the company, the learning material allows the student to actually view the advertisement and visit the related web site to examine various aspects of the company in further detail.

Hypertext links are provided throughout the materials to further examples of the topics under discussion. The student plays is encouraged to play active role in seeking out new examples of the various concepts. An online bibliography facilitates instant access to referenced materials available online and a range of other support materials. Figure 3 illustrates in more detail further elements of the learning materials as displayed on the student's PC. The key to the figure explains each of the numbered elements.

Figure 3 about here

\section{Empirical Study: Assessment of Students’ Attitudes to CIM Materials}

After the module "Current Issues in Marketing" had been taught for two consecutive semesters (October 1999 to February 2000, and March to July 2000), the authors decided to assess the attitudes of the students to the new materials.

It is important to highlight that it was not the intention of this study to examine student performance or learning outcomes with the use of hypermedia materials. Indeed, previous research has concentrated on performance outcomes and has neglected the more affective aspects of technology in distance education (Hara and Kling, 1999; Ahern \& Repman, 1994). The general conclusion from research that focuses on student learning outcomes suggests that students that study in web based environments can learn just as effectively or more than those in the traditional classroom (Hall, 1999; McCollum, 1997, Goldberg, 1997). In any case, all students who study the subject CIM at the UOC have done so with the hypermedia materials. Therefore there was no possibility for comparing the performance of two groups, one who studied with hypermedia and one group who did not. 
Design of the Empirical Study.

A questionnaire was sent out in September of 2000 via email to the 91 students who had taken the subject. Students who did not reply to the first email were sent a reminder three weeks latter. Collection of responses was closed at the end of October 2000.

The response rate was $45,1 \%$ (41 respondents). This was a very satisfactory response given the traditionally low response rate to questionnaires (postal or email based, sent to companies or to individuals) in Spain, even when these have a phone follow-up (Proyecto Cranfield, 2000). The fact that the "Current Issues in Marketing” module is part of the final year of the Business Studies Degree might imply that some of the 91 students had already finished their degree at the UOC. Such students may no longer have been checking their UOC student email. This would imply a real starting set of less than 91 individuals. In any case, the researchers required a minimum of 30 valid responses in order to be able to carry out the t-tests planned in the research design. The 41 replies were more than sufficient.

In line with the project objectives, as formulated from the review of the literature, the research tool measured the following 8 factors (see Annex 1): access to a wide range of support materials (bibliography, complementary readings, examples, etc.); ease of access to support materials; extent to which contents were up-to-date; extent to which materials facilitated the active role of the student in the learning process; extent to which the student preferred an active role in the learning process; suitability of the subject for hypermedia learning materials; extent to which the learning materials had taken advantage of the hypermedia possibilities; and overall evaluation of the use of hypermedia with this module.

Students were asked to range on a scale of 1 (totally agree) to 5 (totally disagree) each of the above factors regarding the learning materials for 'Current Issues in marketing'. Furthermore, students were also asked to indicate, using the same scale, how they felt about the first five factors in relation to 'All Other Subjects' that they had studied at the UOC. This would allow us to compare students' attitudes to the learning materials for 'Current Issues in Marketing' with their general attitudes to the learning materials of other subjects, which are mainly based on paper.

Additionally, it was thought that there might be other criteria important to students in their use of hypermedia materials, but not reflected in the eight factors measured. This might help researchers to identify further specific qualities and characteristics that are relevant for the everyday use of such learning materials by students. Therefore, it was decided to include a final open question enquiring about any comments that the students thought relevant.

\section{Results}

In the first stage of the analysis of the questionnaires a basic set of descriptive data was obtained as shown in Table 1. Using the means of the first five indicators, the student's opinions on Current Issues in Marketing were compared with their opinions on 'All other' subjects they had studied at the UOC. It should be emphasised that all subjects at the UOC are taught in the 'virtual classroom', however the learning materials for most 'Other' subjects are still paper based. 
The data in Table 1 reflect the degree to which students agreed or disagreed with statements such as "I have had easy access to complementary materials and references", "The materials allow an active role in the study of the subject", etc. (see survey instrument in Annex 1). The lower the value, the more the student agreed with the statement. All statements in the questionnaire were worded positively.

Table 1 about here

Observing this descriptive data, it is immediately obvious that overall the students are satisfied with their learning materials at the UOC, as shown by the low means obtained for most measures (all means are below 2.50, both for "Current Issues in Marketing" and "Other Subjects"). Students feel that both the materials for "Current Issues in Marketing" and the materials for "Other Subjects" provide easy and wide access to supporting bibliographies (complementary readings, further examples, etc.) and that the contents are up-to-date.

This initial analysis of the data suggested that the general degree of satisfaction among students left little room for improving the learning experience through the provision of hypermedia materials. Furthermore, these initial results suggested that if any statistically significant difference could be found between the results for 'Current Issues in Marketing' and the results for 'Other Subjects', the implication must be that the new hypermedia materials were actually making a real and worthwhile difference to the learning process. In other words, it would be difficult to improve on a situation in which students were already happy with their learning materials.

The second stage of analysis focused on the possible differences between attitudes to the learning materials of "Current Issues in Marketing" and attitudes to the materials of all “Other Subjects'. The results are shown in Table 2.

Table 2 about here

A student t-test of related means was carried out to compare students' opinions on the five indicators of 'Current Issues in Marketing' and 'Other Subjects'. The results indicate that for three of the five indicators compared there was a statistically significant difference in means, favouring the materials of 'Current Issues in Marketing' (see $t$ values in Table 2).

More specifically, students' opinions were that the learning materials for 'Current Issues in Marketing':

- Provide significantly wider access to related support materials (see t value of -2,477 at a significance of 0,018 ) than other subjects at the UOC;

- Are significantly more up-to-date (t value of $-4,189$, sign. of 0 ) than other subjects; and

- Facilitate a significantly more active role of the student in the learning process $(\mathrm{t}$ value of $-2,838$, sign. 0,007 ) than other subjects.

Interestingly, students felt that the hypermedia learning materials facilitated a more active role of the student in the learning process, but when asked whether they actually preferred a more active role (see last variable in Table 2), the results were inconclusive, 
with many students responding 'indifferent'. Therefore, although the learning materials allow the student to make many decisions for him/herself, the results suggest that they are not quite sure if they like this new way of learning or not.

A final set of three indicators was examined only in relation to 'Current Issues in Marketing'. $70 \%$ of students agreed (totally or mildly) that CIM was particularly suited for hypermedia based learning materials. 68.5\% of students agreed (totally or mildly) that the learning materials had taken maximum advantage of the benefits of hypermedia technology. Finally, and with regard to the global perception students had about the subject's materials, $75 \%$ of students valued positively (totally or mildly) the use of hypermedia with this subject.

A space was provided at the end of the questionnaire to allow students to add any additional comments or opinions. These comments reflect very much the overall satisfaction with the learning materials but they also allow us to examine more closely a number of issues. These issues will be discussed in the following section.

\section{Discussion}

\section{Active Role or Not?}

As mentioned earlier, the responses to the question regarding whether the students actually preferred to take an active role in the learning process were inconclusive. The students' additional remarks allow us to examine this aspect in further detail. Many students suggested that although they liked the 'idea' of taking an active role, in practice they preferred the more traditional, structured, tutor-guided, linear approach.

Students enjoyed seeking out new examples, deciding which web links to follow, which route to follow through the materials, and so on, but they were afraid that they might be missing something or leaving out some important contents or part of the materials. In fact many students printed out all the materials and kept a paper copy to make sure that nothing was overlooked in their preparation for the exam. The following are some representative comments of the students.

"Although its extremely entertaining, at the end of the day I printed out everything to make sure I didn't overlook any section and prepared the 'traditional way' for the exam."

"When you are navigating the net you never know if you are missing something, which is not a problem when you are merely surfing, but when you're studying for an exam it's a different matter."

"I think that even in paper format I can still take an active role and decide the order of study."

"The hyperlinks are great but a printed version would give you a better idea of where you are in terms of the 'whole' material."

The attitudes of students might be compared to visitors to a museum or an art gallery. One visitor ignores the standard route through the building as outlined in the guide to the museum, deciding to take his own route, exploring different sections and rooms at 
his own discretion. Another visitor who knows he will be latter questioned about his visit might fear that by taking his own route through the building he may get lost in a maze of rooms, corridors and sections ('lost in hyperspace'). However by following the standard route set out by the museum he is sure not to miss out on any section and he increases his chances of being able to answer questions at the end of his visit. Thus student's apprehension at adopting a proactive role in 'surfing' the hypermedia materials is consistent with the risk of being 'lost in hyperspace' as outlined in the literature review (Burbules \& Callister, 1996).

\section{Traditional Paper Format or Hypermedia Format?}

The students' comments suggest that the ideal learning material should not be a choice between the traditional paper-based and the newer hypermedia-based materials, but should instead be a combination of the two formats. They liked the opportunity to see the actual advertisements with the hypermedia materials instead of just reading about them in paper based materials. They liked viewing the video clips, visiting the web pages of the companies mentioned and reading related online materials.

Nevertheless, they felt that the computer screen was not entirely suited to studying (you cannot take the computer screen to read in bed or in the metro) and the technology did not allow them to underline or highlight important sections or incorporate their own comments directly into the materials. With paper materials students use highlighter markers to identify more important sections and they scribble short notes into the margins and between paragraphs. The technology of web pages does not as yet allow this type of personalisation of the learning materials on the computer screen.

"The only problem is the absence of a printed version, not to replace but to complement the hypermedia materials."

"Hypermedia has great advantages, but so does paper. I don't understand why we have to chose one or the other."

"I really enjoyed the multimedia features but it was frustrating not being able to underline or add my own notes."

\section{Conclusions}

In terms of student attitudes to the hypermedia learning materials the CIM project was a success. As mentioned earlier, this study did not examine student grade performance for this module. Indeed, student performance on hypermedia versus paper media marketing modules would be an interesting line for future research.

The hypermedia learning materials achieved the primary objectives of the CIM project of widening and easing access to supporting bibliographies, of providing up-to-date learning contents and of facilitating the active role of the student in the learning process. Furthermore, students agreed that studying Marketing was particularly suited to hypermedia learning materials, and was in general valued more highly than other paperonly materials.

However, we must not be 'blinded by science'. Hypermedia improves old or traditional learning materials but it should not replace them. Traditional paper-based materials are 
extremely well suited to the learning process. New technologies and new materials should be used in combination with existing formats.

Two main issues emerge from the discussion, (i) whether or not students welcome the proactive role required with hypermedia materials or whether they will resort to printing out all the materials and arranging them in a linear order, and (ii) how can the existing hypermedia technology be adapted to student learning or studying methods (thus facilitating note taking, underlining, highlighting, and keeping a record of the sections or links already visited, etc.).

It is the authors' view that these two issues are closely linked and that a solution to the technological limitations of web based hypermedia materials could also provide a solution for the student who wants to adopt a proactive role but is faced with the more immediate task of studying for an exam. A simple and immediate solution would involve students being provided with a paper based study plan (just like the guide to the museum) by their professor. This study plan or guide should summarise the contents of the hypermedia materials in the form of a simple flow diagram. This guide should also highlight the most important sections of the materials and clearly list the 'must not be overlooked' sections or topics. In this way the student can take the liberty of 'exploring' the materials with the knowledge that by the end of the semester he must have visited at least the sections highlighted in his study guide. This guide is in the process of being implemented for Current Issues in Marketing at the UOC.

As mentioned earlier, some students resort to printing out page by page the contents of the materials. As the format is based on web pages (more pages with less text per page than paper materials) this is an unenviable task which takes up many valuable study hours. However, the authors and designers of the materials did not create them with a linear reading approach in mind. Therefore students have been discouraged from simply printing the whole materials, page by page. The authors suggest that the simple solution to this dilemma is to provide a printable (pdf type) version of the materials as well as the 'student study guide'. In this way students who wish to highlight or underline certain sections or printout certain pages can do so at their own ease and discretion.

Probably a mid term solution would involve developing a web based technology which would also students to personalise their learning materials by facilitating notes taking, underlining and highlighting directly on the computer screen.

Hypermedia learning materials are being used more and more in distance education. With each successive project we are incorporating the lessons learned from previous projects. It is clear that the use of hypermedia can enrich the learning process, particularly for subjects such as marketing for which a combination of images, videos of advertisement and company's web pages all contribute to improving the overall learning experience.

Finally, hypermedia technologies are advancing all the time and are successively more closely in tune with the learning needs and styles of students. At the same time, the need to incorporate technology into marketing education is increasingly a requirement in both distance and non-distance education. "The advent of courses that exist in virtual worlds will increasingly require that all marketing educators will embrace the technological changes that are sure to continue” (Smart et al 1999, p. 206). In order to 
achieve greater cohesion between technology and student learning styles, more empirically based research must be carried out on the actual use of hypermedia materials by students. The only way to advance is to actually look at how students use these materials in practice. 


\section{References}

Abrahamson, C.E (1998). Issues in interactive communication in distance education. College Student Journal, 32 (1), pp.33-43.

Ahern, T.C. \& J. Repman (1994). The effects of technology on online education. Journal of Research on Computing in Education, 26 (4), pp.537-546.

Aparicio-Valverde, M.; A. Pagès, \& G. Ryan (1996). Learning strategies at the Virtual University: the case of the Open University of Catalonia (UOC). Proceedings of the conference The Virtual University? London, U.K.: Higher Education for Capability.

Besser, H. \& S. Donahue (1996). Introduction and overview: perspectives on ... distance independent education. Journal of the American Society for Information Science, 47 (11), pp.801-804.

Borges, F. (1998) UOC and its Virtual Campus: a model for online university education. North American Web Developers Conference. Available at http://naweb.unb.ca/proceedings/1998/borges/borges.htm

Burbules, N.C. \& T.A. Callister (1996).Knowledge at the crossroads: Some alternative futures of hypertext learning environments. Educational Theory, 46, pp.23-50.

Butler, B.S (1997). Using the world wide web to support classroom-based education: Conclusions from a multiples case study. In B.H Khan (Ed). Web based instruction, Englewood Cliffs, NJ: Educational Technology Publications.

Cooke, J. \& I. Veach (1997). Enhancing the learning outcome of university distance education: An Australian perspective. The International Journal of Educational Management, 11 (5).

European Commission, DG XXII (1988). Open and distance learning in action. Available at http://www.europa.eu.int/comm/education/index_en.html

Goldberg, M.W. (1997). CALOS: First results from an experimental in computer-aided learning. Proceedings of the ACM's $28^{\text {th }}$ SIGCSE Technical Symposium on Computer Science Education.

Hall, R.H (1999). Instructional web site design principles: A literature review and synthesis. Virtual University Journal, 2 (1). Available June 2001 at http://www.openhouse.org.uk/virtual-university-press/vuj

Hagan (1995). "User preferences in open and distance language learning. What are the options for multimedia?", ReCall, 7(1), 20-25.

Hara, N. \& R. Kling (1999). Students' frustrations with a web based distance education course. First Monday, 4 (12). Also available May 2001 at http:// firstmonday.org/issues/issue4_12/hara/index.html 
Hill, J.R (1997). Distance learning environments via the world wide web. In B.H Khan (Ed). Web based instruction, Englewood Cliffs, NJ: Educational Technology Publications.

Holmberg, B. (1995). "The evolution of the character and practice of distance education", Open Learning, 10(2), 47-53.

Jefferies, P. \& F. Hussain (1998). Using the internet as a teaching resource. Education and Training, $40(8)$.

Johnston, R. (1997). "Distance Learning medium or message," Journal of Further and Higher Education, 21 (1), 107-120.

Jones, S.G. (1995). "Understanding community in the information age", in S.G Jones (Ed), "Cybersociety: Computer-mediated communication and community," 10-35. Thousand Oaks, California: Sage Publications.

Kember, D. (1989). A longitudinal process model of dropout from distance education. Journal of Higher Education, 60, pp.278-301.

Kolosseus, B. \& D. Bauer \& S.A. Bernhardt (1995). From writer to designer: Modelling composing processes in a hypertext environment. Technical Communication Quarterly, 4, pp.79-93.

Levin, S.R \& G.L. Waddoups (2000). CTER online providing highly interactive and effective online learning environments. Available May 2001 at:

http://faculty.ed.uiuc.edu/slevin/site2000.html

Martinez, M. (2000). Successful web learning environments: New design guidelines. Available through the ERIC database.

McCollum, K. (1997). A professor divides his class in two to test value of on-line instruction. The Chronicle of Higher education, 43 (24).

Meacham, D., and D. Evans (1989). "Distance Education: The Design of Study Materials." Wagga Wagga: Open Learning Institute, Charles Sturt University.

Proyecto Cranfield (2000). Estudio Cranfield-ESADE. Gestión Estratégica de Recursos Humanos. Una década de investigación. Informe de Conclusiones. Barcelona (Spain): ESADE.

Sangrà, A (2001). Present and future use of technologies in education. Lecture presented at the IV Open Classroom Conference: EDEN (European Distance Education Network. Barcelona, November 2000. Available April 2001 at http://www.uoc.es/web/cat/art/uoc/0103009/sangra_imp.html

Smart, D. \& C.A. Kelley \& S. Conant (1999). Marketing education in the year 2000. Changes observed and challenges anticipated. Journal of Marketing education, 21 (3), pp.206-216. 
TEEODE Project, Open and Distance Learning Programme, SOCRATES European Project (1998). "Technology enhanced evaluation in open and distance education" (Universitat de Barcelona, Universitat zu Köln, Université de Liège, terza Università degli Studi di Roma, UNiversity of Leicester, Universidade Aberta; partially financed by the European Comission). [online] Available at http://wwwdoe.d5.ub.es/te/teeode/THEBOOK/OPENME:HTM

The Further Education Funding Council (FEFC) (1997). How to apply for funding. Bristol. Further Education Council.

Twigg, C.A (1997). Is technology a silver bullet? Educom review, March-April, pp.2829.

Viali, L. (1998). Hypermedia system to teach statistics. Paper presented at the International Conference on Engineering Education. Rio de Janeiro, Brazil, August 1720.

Warden, V. (1995) The first virtual campus? Financial Times. $3^{\text {rd }}$ October, p. 24. Also, see ccat.sas.upenn.edu/jod/texts/catalan.html

Weiland, W.J. and B. Shneiderman (1989). "Interactive graphics in hypertexts systems" in $28^{\text {th }}$ Annual ACM DC Technical Symposium [on-line]. Maryland: University of Maryland. Available at http://www.cs.umd.edu/projects/hcil 


\section{Annex 1}

\section{Questionnaire on the Learning Materials for Current Issues in Marketing}

Indicate on a scale of 1 to 5 the extent to which you agree with the following statements, where $1=$ totally agree; 2 = mildly agree; 3 = indifferent; 4 = mildly disagree; and 5 = totally disagree.

It is important to indicate your opinion for statements 1 to 5 in both Columns A and B.

- In Column A, indicate your opinion of the learning materials for 'Current Issues in Marketing'.

- In Column B indicate your overall opinion in terms of the learning materials of all the other courses you have taken at the UOC.

\begin{tabular}{|l|l|l|}
\hline & $\begin{array}{c}\text { Current Issues in } \\
\text { Marketing }\end{array}$ & $\begin{array}{c}\text { All Other Subjects } \\
\text { studied at the UOC }\end{array}$ \\
\hline $\begin{array}{l}\text { 1. I had access to a wide range of associated learning } \\
\text { materials (i.e. suggested bibliography, complementary } \\
\text { readings, examples, etc.) }\end{array}$ & \\
\hline $\begin{array}{l}\text { 2. I had easy access to associated learning materials (i.e. } \\
\text { suggested bibliography, complementary readings, examples, } \\
\text { etc.) }\end{array}$ & & \\
\hline 3. The subject contents were up-to-date & \\
\hline $\begin{array}{l}\text { 4. The learning materials facilitated a proactive role on the } \\
\text { part of the student in the learning process (e.g. order of study } \\
\text { of materials, decisions on which web pages and examples to } \\
\text { read, in which order and which other resources to use) }\end{array}$ & & \\
\hline $\begin{array}{l}\text { 5. I prefer to adopt a proactive role in the study of my } \\
\text { courses instead of following a standard set of learning } \\
\text { materials with a set lineal reading order. }\end{array}$ & & \\
\hline
\end{tabular}

For questions 6 to 8, please give your opinion ONLY for the subject Current Issues in Marketing.

\begin{tabular}{|l|l|}
\hline & Current Issues in Marketing \\
\hline $\begin{array}{l}\text { 6. "Current Issues in Marketing” is particularly suited to } \\
\text { hypermedia learning materials. }\end{array}$ & \\
\hline $\begin{array}{l}\text { 7. The learning materials have taken full advantage of the } \\
\text { possibilities of hypermedia to facilitate the learning of the } \\
\text { subject contents. }\end{array}$ & \\
\hline $\begin{array}{l}\text { 8. In general I value positively the use of hypermedia } \\
\text { learning materials for this subject. }\end{array}$ & \\
\hline
\end{tabular}

9. Please add any further comments that you feel are relevant in relation to the study of Current Issues in Marketing with hypermedia materials. 